Check for updates

Cite this: RSC Adv., 2018, 8, 10922

Received 15th December 2017 Accepted 25th February 2018

DOI: $10.1039 / c 7 r a 13362 f$

rsc.li/rsc-advances

\section{Preparation and investigation of highly selective solid acid catalysts with sodium lignosulfonate for hydrolysis of hemicellulose in corncob $\uparrow$}

\author{
Xun Li,,$^{a}$ Fengyao Shu, ${ }^{\text {ab }}$ Chao He, ${ }^{\text {b }}$ Shuna Liu, $\dot{t}^{\mathrm{b}}$ Noppol Leksawasdi, ${ }^{\mathrm{C}}$ \\ Qiong Wang, (D) *b Wei Qi, (D)*b Md. Asraful Alam, ${ }^{\text {b }}$ Zhenhong Yuan $^{\text {bd }}$ and Yi Gao ${ }^{\mathrm{e}}$
}

Saccharification of lignocellulose is a necessary procedure for deconstructing the complex structure for building a sugar platform that can be used for producing biofuel and high-value chemicals. In this study, a carbon-based solid acid catalyst derived from sodium lignosulfonate, a waste by-product from the paper industry, was successfully prepared and used for the hydrolysis of hemicellulose in corncob. The optimum preparation conditions for the catalyst were determined to be carbonization at $250{ }^{\circ} \mathrm{C}$ for $6 \mathrm{~h}$, followed by sulfonation with concentrated $\mathrm{H}_{2} \mathrm{SO}_{4}(98 \%)$ and oxidation with $10 \% \mathrm{H}_{2} \mathrm{O}_{2}$ (solid-liquid ratio of $1: 75 \mathrm{~g} \mathrm{~mL}^{-1}$ ) at $50{ }^{\circ} \mathrm{C}$ for $90 \mathrm{~min}$. SEM, XRD, FT-IR, elemental analysis and acid-base titration were used for the characterization of the catalysts. It was found that $0.68 \mathrm{mmol} \mathrm{g}^{-1} \mathrm{SO}_{3} \mathrm{H}$ and $4.78 \mathrm{mmol} \mathrm{g}^{-1}$ total acid were loaded onto the catalyst. When corncob was hydrolyzed by this catalyst at $130{ }^{\circ} \mathrm{C}$ for $12 \mathrm{~h}$, the catalyst exhibited high selectivity and produced a relatively high xylose yield of up to $84.2 \%$ (W/ w) with a few by-products. Under these conditions, the retention rate of cellulose was $82.5 \%$, and the selectivity reached $86.75 \%$. After 5 cycles of reuse, the catalyst still showed high catalytic activity, with slightly decreased yields of xylose from $84.2 \%$ to $70.7 \%$.

\section{Introduction}

Due to the emergence of environmental and energy issues, researchers and biofuel stockholders have devoted significant attention towards the conversion of lignocellulose into biofuels and high-value compounds. ${ }^{1-3}$ Acid-catalyzed hydrolysis has been considered as one of the most efficient pretreatment approaches for delignification of lignocellulose by deconstruction of the complex structure to release the high yield of C5/C6 sugars for the preparation of important derivatives, such as bioethanol and high-value-added chemicals.,5 Liquid acid catalysis is the commonly adopted method for the pretreatment or hydrolysis of lignocellulose; however, this method is not only corrosive and non-recyclable but also leads to the further degradation of sugars. ${ }^{6-8}$

\footnotetext{
${ }^{a}$ Changsha University of Science and Technology, Changsha, 410004, China

${ }^{b}$ Guangzhou Institute of Energy Conversion, Chinese Academy of Sciences, CAS Key Laboratory of Renewable Energy, Guangdong Key Laboratory of New and Renewable Energy Research and Development, Guangzhou, 510640, China. E-mail: qiwei@ms. giec.ac.cn; wangqiong@ms.giec.ac.cn

'Faculty of Agro-Industry Chiang Mai University, Chiang Mai, 50100, Thailand ${ }^{d}$ Collaborative Innovation Centre of Biomass Energy, Zhengzhou, 450002, China ${ }^{e}$ Henan Academy of Sciences Institute of Energy Co. Ltd., Zhengzhou 450000, China $\dagger$ Electronic supplementary information (ESI) available. See DOI: $10.1039 / \mathrm{c} 7 \mathrm{ra} 13362 \mathrm{f}$

$\$$ These authors contribute equally to this work.
}

Research on the preparation of solid acid catalysts and their utilization in lignocellulose conversion has been carried out in recent years with the hope of solving the problems brought on by liquid acid catalysis. ${ }^{9}$ At present, the commonly used solid acids can be divided into the following categories: zeolite molecular sieves, ${ }^{\mathbf{1 0}}$ heteropoly acids, ${ }^{\mathbf{1 1}}$ metal oxides and their complexes, ${ }^{12}$ inorganic acid salts, ${ }^{13}$ strong acid cation exchange resins ${ }^{14}$ and carbon-based solid acids. ${ }^{15}$

Research on carbon-based solid acids has received wide attention due to the relatively higher catalytic efficiency, good stability, environmental friendliness, low price and renewability ${ }^{\mathbf{1 6}}$ of these catalysts. The carbon-based solid acid is a new type of solid acid obtained by introducing sulfonic acid groups onto the carbon material. ${ }^{17}$ Due to the rich presence of acidic functional groups $\left(-\mathrm{SO}_{3} \mathrm{H},-\mathrm{COOH},-\mathrm{OH}\right)$, carbon-based solid acids can efficiently adsorb the $\beta-1,4$ glycosidic bond and can subsequently depolymerize it effectively. ${ }^{18}$ This characteristic mitigated activation energy greatly enhances the efficient hydrolysis of cellulose. ${ }^{16,19}$ Suganuma ${ }^{17}$ used sucrose and glucose as raw materials and subjected them to carbonization at $300^{\circ} \mathrm{C}$ and subsequent sulfonation to obtain a solid acid catalyst. $\operatorname{Lian}^{20}$ prepared a new catalyst via hydrothermal carbonization of fructose and sulfosalicylic acid, which resulted in a reduced sugar yield of $60.7 \%$ for the hydrolysis of cellulose at $130{ }^{\circ} \mathrm{C}$ for $90 \mathrm{~min}$ in ionic liquid. Shen ${ }^{21}$ prepared a solid acid by sulfonation of carbonized starch and polyvinyl chloride. The corresponding yield of glucose was $44.76 \%$ for cellobiose hydrolysis at $120^{\circ} \mathrm{C}$ for $6 \mathrm{~h}$. 
Due to the complicated structure of lignocellulosic biomass, unsatisfactory results were often obtained in the application of carbon-based solid acids for lignocellulose saccharification or fractionation. Zhang prepared the solid acid catalyst $\mathrm{Fe}_{3} \mathrm{O}_{4} / \mathrm{C}-$ $\mathrm{SO}_{3} \mathrm{H}$ to catalyze corncob hydrolysis; $44.3 \%$ xylose yield was obtained at $160{ }^{\circ} \mathrm{C}$ for $16 \mathrm{~h}^{22} \mathrm{Xu}^{23}$ used glucose and $p$-toluenesulfonic acid as raw materials to prepare solid acid $\left(\mathrm{Gp}-\mathrm{SO}_{3} \mathrm{H}-\right.$ $\mathrm{H}_{2} \mathrm{O}_{2}$ ) for corncob hydrolysis and obtained a 77.5\% xylose yield under the optimal condition. Zhong ${ }^{24}$ prepared the $\mathrm{SO}_{4}{ }^{2-} / \mathrm{Fe}_{2} \mathrm{O}_{3}$ solid acid catalyst and catalyzed the hydrolysis of wheat straw; $63.5 \%$ of xylose was obtained after the treatment of hydrolysate with $1 \mathrm{M} \mathrm{H}_{2} \mathrm{SO}_{4}$ at $100{ }^{\circ} \mathrm{C}$ for $1 \mathrm{~h}$.

In this study, we used sodium lignosulfonate, a waste material from sulphite pulp, to prepare highly selective carbonbased solid acid catalysts, which can directly catalyze hemicellulose from biomass into xylose. Moreover, this study is different from the reported studies on random acquisition of xylo-oligosaccharides during the hydrolysis of lignocellulose catalysed by carbon-based solid catalysts. Recently, researchers found that lignosulfonates were rich in aromatic ring structures and could be modified to produce an effective carbon-based solid acid catalyst. ${ }^{25} \mathrm{Zhu}^{26}$ approached cellulose hydrolysis by lignosulfonate-based solid acid and obtained a total sugar yield of $44.2 \%$. However, there are few publications regarding lignosulfonate-derived carbon-based solid catalysts for lignocellulose hydrolysis.

We used sodium lignosulfonate as the carbon base and prepared three kinds of solid acid catalysts. The solid acid catalysts were used for corncob hydrolysis, and a high yield $(84.2 \%)$ of xylose was directly obtained with a few by-products under mild reaction conditions. The retention rate of cellulose in the residue was $82.5 \%$. This process fully utilized lignosulfonate by-products of sulfite pulp to prepare a carbonbased solid acid catalyst with high catalytic activity and selectivity for the hydrolysis of hemicellulose to xylose. The high retention of cellulose is also an important resource for ethanol and a platform for chemicals production.

\section{Experimental}

\section{Materials}

Sodium lignosulfonate (96\%, 534.15 MW) was purchased from Shanghai Macklin Biochemical Ltd (China). Sulfuric acid (AR), hydrochloric acid and hydrogen peroxide (30 wt\%, AR) were obtained from Guangzhou Chemical Reagent Factory (China). D-Xylose (AR) and calcium carbonate (AR) were purchased from Tianjin Fuchen Chemical Reagent Factory (China). All reagents were used without purification. Corncob powder was acquired from a farm in Shandong Province, China. It was ground into particles with a size of 40-60 mesh and then oven-dried at $80^{\circ} \mathrm{C}$ for $12 \mathrm{~h}$.

\section{Preparation of catalyst}

Under a nitrogen atmosphere, sodium lignosulfonate (denoted as $\mathrm{Sl}$ ) was carbonized at $200-300{ }^{\circ} \mathrm{C}$ for $2-8 \mathrm{~h}$ in a homemade tube furnace (shown in Fig. S1 $\dagger$ ). After carbonization, the powder was washed with deionized (DI) water until the filtrate was colorless and then, the filtrate was dried at $105{ }^{\circ} \mathrm{C}$ overnight. This black powder was denoted as Sl-C.

One gram of Sl-C was mixed with $50 \mathrm{~mL}$ of $6 \mathrm{M}$ hydrochloric acid on a shaking table (QHZ-3B) at $150 \mathrm{ppm}$ and at $30{ }^{\circ} \mathrm{C}$ for $4 \mathrm{~h} .{ }^{27}$ It was then washed with a large amount of DI water until the $\mathrm{pH}$ was neutral and then, it was dried at $105^{\circ} \mathrm{C}$ for $6 \mathrm{~h}$. This sample was denoted as Sl-C-H.

One gram of Sl-C and $20 \mathrm{~mL}$ of $\mathrm{H}_{2} \mathrm{SO}_{4}(98 \mathrm{wt} \%$ ) were added to a $75 \mathrm{~mL}$ thick-walled pressure bottle (Beijing Synthware Glass Co. Ltd.) and reacted at $130{ }^{\circ} \mathrm{C}$ in an oil bath for $10 \mathrm{~h}$. Then, the powder was washed with DI water until the $\mathrm{pH}$ was neutral. The product was dried in an oven at $105^{\circ} \mathrm{C}$ for $6 \mathrm{~h}$ and was denoted as Sl-C-S.

One gram of Sl-C-S and $\mathrm{H}_{2} \mathrm{O}_{2}(0-30 \mathrm{wt} \%)$ were mixed in the solid/liquid ratio of $1: 25-1: 125(m: v)$ and reacted for 30$150 \mathrm{~min}$ at $30-70{ }^{\circ} \mathrm{C}$ in a $150 \mathrm{~mL}$ thick-walled pressure bottle (Beijing Synthware Glass Co. Ltd.). Then, the powder was treated via the procedures described above and denoted as Sl-C$\mathrm{S}-\mathrm{H}_{2} \mathrm{O}_{2}$.

\section{Hydrolysis of corncob}

First, $0.3 \mathrm{~g}$ of catalyst, $0.3 \mathrm{~g}$ of corncob and $30 \mathrm{~mL}$ of DI water were loaded into a $75 \mathrm{~mL}$ thick-walled pressure bottle, and this solution was maintained at $130{ }^{\circ} \mathrm{C}$ in an oil bath for $12 \mathrm{~h}$. Then, the solution was centrifuged at $8000 \mathrm{rpm}$ for $3 \mathrm{~min}$. Part of the supernatant was treated with $4 \mathrm{wt} \% \mathrm{H}_{2} \mathrm{SO}_{4}$ to depolymerize the oligosaccharides. Next, $5 \mathrm{~mL}$ of the untreated supernatant and $5 \mathrm{~mL}$ of the $4 \mathrm{wt} \% \mathrm{H}_{2} \mathrm{SO}_{4}$-treated supernatant were neutralized with $\mathrm{CaCO}_{3}$, and they were then analyzed by high-performance liquid chromatography (HPLC).

\section{Characterization of catalyst}

The functional groups of the catalysts were analyzed by Fouriertransform infrared spectroscopy (FT-IR) using a TENSOR 27 spectrometer (Bruker) in the range of $400-4000 \mathrm{~cm}^{-1}$. The powder X-ray diffraction patterns were obtained in the $2 \theta$ range of $5-80^{\circ}$ with a scanning step of $0.0167^{\circ}$ using a PANalytical X'Pert PRO (Cu Ka1 radiation), operating at $40 \mathrm{kV}$ and $40 \mathrm{~mA}$. The surface morphology of the catalyst was observed by scanning electron microscopy (SEM, S-4800, Hitachi, Japan). The C, $\mathrm{H}, \mathrm{N}$, and $\mathrm{S}$ elemental contents were detected by an elemental analyser (Vario EL cube, Germany). The acid functional groups in the catalyst were determined by acid-base titration. ${ }^{23}$ First, the total amount of acid in the catalyst was titrated as follows: $0.25 \mathrm{~g}$ catalyst was added to $40 \mathrm{~mL}$ of $0.05 \mathrm{M}$ sodium hydroxide, and this solution was put on a shaking table for $4 \mathrm{~h}$ at $50{ }^{\circ} \mathrm{C}$ to react $\mathrm{HO}^{-}$and the acid group on the catalyst. After centrifugation at $8000 \mathrm{rpm}$ for $3 \mathrm{~min}, 10 \mathrm{~mL}$ of the supernatant was titrated with $0.05 \mathrm{M}$ hydrochloric acid to evaluate the total amount of acid in the catalyst. The catalyst $(0.25 \mathrm{~g})$ was also added to $40 \mathrm{~mL}$ of $0.05 \mathrm{M}$ sodium chloride under the same conditions to fully exchange $\mathrm{Na}^{+}$and $\mathrm{H}^{+}$on the $\mathrm{SO}_{3} \mathrm{H}$ group. After centrifugation at $8000 \mathrm{rpm}$ for $3 \mathrm{~min}, 10 \mathrm{~mL}$ of the supernatant was titrated with $0.05 \mathrm{M}$ sodium hydroxide to evaluate the concentration of $\mathrm{SO}_{3} \mathrm{H}$ groups on the catalyst. 


\section{Analytical methods}

The chemical composition of the raw material was analyzed according to the standard laboratory analytical procedures (LAP) for biomass analysis provided by the US National Renewable Energy Laboratory (NREL). ${ }^{28}$ The analysis revealed that the corncob was composed of $35.07 \%$ glucan, $34.54 \%$ xylan, and $14.14 \%$ lignin (dry weight basis).

The xylose and by-products were identified by HPLC (Waters 2695) using a Shodex SH-1011 column, and $5 \mathrm{mM} \mathrm{H}_{2} \mathrm{SO}_{4}$ was employed as the mobile phase with a flow rate of $0.5 \mathrm{~mL} \mathrm{~min} \mathrm{~m}^{-1}$ at $50{ }^{\circ} \mathrm{C}$. Calibration curves were established for quantitative calculations.

The xylose yield $\left(Y_{\mathrm{x}}\right)$, xylose conversion rate $\left(C_{\mathrm{x}}\right)$ and xylose selectivity $\left(S_{\mathrm{x}}\right)$ were calculated by eqn (1), (2) and (3).

$$
Y_{\mathrm{x}}(\%)=\frac{\text { mass of xylose in the hydrolysate }}{\text { mass of xylose in corncob }} \times 100 \%
$$

$C_{\mathrm{x}}(\%)=$

mass of xylose in corncob - mass of xylose in the residue mass of xylose in corncob

$\times 100 \%$

$$
S_{\mathrm{x}}(\%)=\frac{Y_{\mathrm{x}}}{C_{\mathrm{x}}} \times 100 \%
$$

The crystallinity calculation equation is as follows: ${ }^{29}$

$$
\mathrm{CrI}=\frac{I_{\text {crystalline }}(002)-I_{\text {amorphous }}(101)}{I_{\text {amorphous }}(002)} \times 100 \%
$$

here, CrI is the crystallinity of cellulose, $I_{\text {crystalline }}(002)$ is the strength of the crystalline region $\left(2 \theta=22.5^{\circ}\right)$ and $I_{\text {amorphous }}(101)$ is the strength of the amorphous region $\left(2 \theta=17.5^{\circ}\right)$.

\section{Results and discussion}

\section{Evaluation of catalyst activity}

Comparative analyses of the catalytic activities of the three catalysts (Sl-C-H, Sl-C-S, Sl-C-S- $\mathrm{H}_{2} \mathrm{O}_{2}$ ) were carried out. The carbonization reaction using each of the three catalysts was carried out at $250{ }^{\circ} \mathrm{C}$ for $6 \mathrm{~h}$, and the subsequent oxidation process comprised $1 \mathrm{~g}$ of Sl-C-S reacted with $75 \mathrm{~mL} 10 \% \mathrm{H}_{2} \mathrm{O}_{2}$ at $50{ }^{\circ} \mathrm{C}$ for $90 \mathrm{~min}$. To evaluate the catalytic activity of each catalyst, the reaction conditions did not facilitate complete reaction for any of the catalysts. As shown in Fig. 1, for Sl-C-H, the direct xylose yield was $21 \%$, and the xylose yield was $62 \%$ after $4 \mathrm{wt} \%$ sulfuric acid treatment, indicating that most of the xylan in hemicellulose was hydrolyzed into xylooligosaccharides. For Sl-C-S catalysis, the xylose yield increased from $58.2 \%$ to $77 \%$ before and after $4 \mathrm{wt} \%$ sulfuric acid treatment, indicating that there was still a significant amount of xylo-oligosaccharides produced. From this, it could be seen that both of these two catalysts were less selective for the hydrolysis of hemicellulose to monosaccharides (xylose). However, for the catalytic hydrolysis of Sl-C-S- $\mathrm{H}_{2} \mathrm{O}_{2}$, the yield of

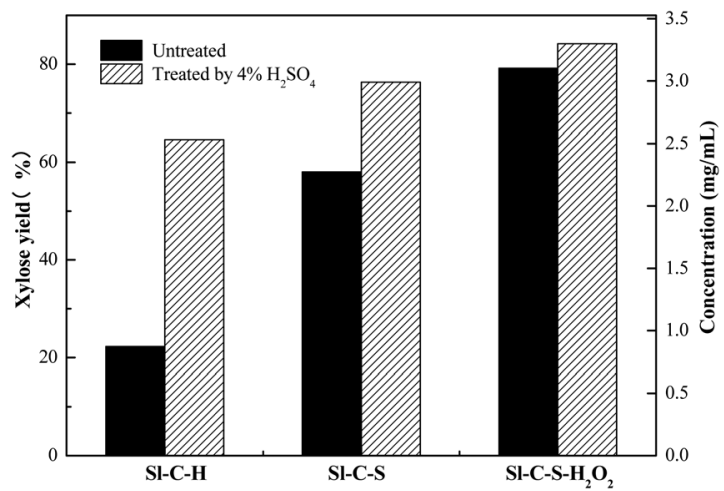

Fig. 1 Xylose yields from corncob hydrolysis catalysed by three catalysts.

xylose did not change much before and after $4 \mathrm{wt} \%$ sulfuric acid treatments, only changing from $78 \%$ to $84.2 \%$, which indicated the high selectivity of Sl-C-S- $\mathrm{H}_{2} \mathrm{O}_{2}$ for the hydrolysis of hemicellulose to monosaccharides (xylose), and the selectivity reached $86.75 \%$ after calculation.

Small amounts of by-products such as glucose, arabinose, furfural, glucuronic acid and acetic acid were also detected (Fig. S2 $\dagger$ ) in hydrolysate. As reported, the presence of these byproducts was inevitable during the hydrolysis of lignocellulose. ${ }^{\mathbf{4} 24}$ Furfural was the degradation product of xylose or xylooligosaccharide. According to the eqn (3), the selectivity of xylose was calculated to be $86.75 \%$. The selectivity of total saccharides (xylose and xylo-oligosaccharide) was calculated to be $93.65 \%$, which also indicated the high selectivity of the catalyst during the hydrolysis of corncob.

To identify the relationship between the components of the three catalysts and the xylose yield, elemental and total acid analyses were performed. As shown in Table 1, the solid acid Sl$\mathrm{C}-\mathrm{H}$ revealed the weakest acidity, which accounted for the least effective catalytic performance. Upon comparison of the chemical formula of Sl-C-S $\left(\mathrm{CH}_{0.787} \mathrm{O}_{0.505} \mathrm{~S}_{0.016}\right)$ with that of Sl-C$\mathrm{H}\left(\mathrm{CH}_{0.841} \mathrm{O}_{0.344} \mathrm{~S}_{0.006}\right)$, it was observed that the sulfur content of Sl-C-S was significantly higher than that of Sl-C, which was due to the $\mathrm{SO}_{3} \mathrm{H}$ groups introduced by the reaction between Sl-C and concentrated sulfuric acid. The sulfonic acid group was the most effective group for corncob hydrolysis; ${ }^{18}$ thus, the catalytic activity of Sl-C-S was higher than that of Sl-C-H, resulting in a further increase in xylose yield. After the oxidation reaction, the chemical formula of Sl-C-S- $\mathrm{H}_{2} \mathrm{O}_{2}$ was $\mathrm{CH}_{0.769} \mathrm{O}_{0.539} \mathrm{~S}_{0.016}$. The oxygen content of Sl-C-S- $\mathrm{H}_{2} \mathrm{O}_{2}$ was the highest among the

Table 1 Elemental analyses and acid-base titration results of the three solid acid catalysts

\begin{tabular}{lllll}
\hline Catalyst & $\begin{array}{l}\text { Sulfur } \\
\text { content }(\%)\end{array}$ & $\begin{array}{l}\text { Oxygen } \\
\text { content }(\%)\end{array}$ & $\begin{array}{l}-\mathrm{SO}_{3} \mathrm{H} \\
\text { content } \\
\left(\mathrm{mmol} \mathrm{g}^{-1}\right)\end{array}$ & $\begin{array}{l}\text { Total acid } \\
\text { content } \\
\left(\mathrm{mmol} \mathrm{g}^{-1}\right)\end{array}$ \\
\hline Sl-C-H & 0.971 & 29.755 & 0.30 & 2.15 \\
Sl-C-S & 2.706 & 37.664 & 0.70 & 4.40 \\
Sl-C-S- $\mathrm{H}_{2} \mathrm{O}_{2}$ & 2.364 & 39.359 & 0.68 & 4.78
\end{tabular}


three catalysts. This may be due to the introduction of carboxylic acid groups and hydroxyl functional groups during the oxidation reaction by hydrogen peroxide, which could also account for its highest total acid content.

\section{Characterization of catalysts}

The surface morphologies of Sl, Sl-C-H, Sl-C-S and Sl-C-S- $\mathrm{H}_{2} \mathrm{O}_{2}$ are shown in Fig. 2. From the SEM micrographs, it could be found that there were obvious changes through every step in the syntheses of the catalysts. The smooth surface of $\mathrm{Sl}$ is shown in Fig. 2(a). After carbonization at $250^{\circ} \mathrm{C}$, surface cracks appeared as shown in Fig. 2(b), which was attributed to the breakage of chain structures such as ether linkages. ${ }^{27}$ After the sulfonation reaction with concentrated sulfuric acid (Fig. 2(c)), the particle size decreased and the particles tended to aggregate. Moreover, many gullies and pores on the surface of the catalyst were observed. However, the $\mathrm{H}_{2} \mathrm{O}_{2}$ oxidation did not significantly change the surface structure (Fig. 2(d)), indicating that this type of oxidation process had less impact on the surface morphology of the catalyst.

The XRD patterns of Sl-C-H, Sl-C-S and Sl-C-S- $\mathrm{H}_{2} \mathrm{O}_{2}$ are shown in Fig. 3. It could be observed that there was no great difference between the skeleton structures of these three catalysts. The XRD patterns of all three catalysts had two diffraction peaks. One broad diffraction peak was observed at a $2 \theta$ angle of $10-30^{\circ}$, which was attributed to the (002) plane of the amorphous carbon framework. Another weak diffraction peak was observed between $35^{\circ}$ and $50^{\circ}$ which was ascribed to the (101) plane of the amorphous carbon framework corresponding to the $\alpha$-axis direction of the graphite structure. ${ }^{30}$ After the sulfonation reaction, the peak at $10-30^{\circ}$ became weaker, reflecting further dehydration by concentrated acid. ${ }^{26}$

The FT-IR spectra of $\mathrm{Sl}$ and the three catalysts are shown in Fig. 4. The peak at $1217 \mathrm{~cm}^{-1}$ in the raw materials arose from the stretching vibration of the ether bond (C-O-C). However, this peak disappeared after the carbonization process, which was due to the high-temperature fracture of the ether bond and the corresponding production of small molecules. The characteristic peak at

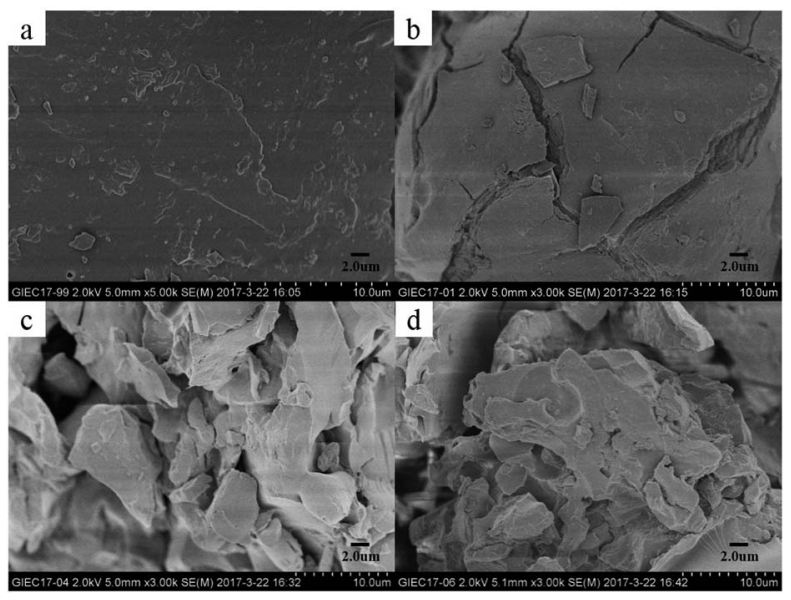

Fig. 2 Scanning electron microscopy images of the catalysts. (a) Sl, (b) $\mathrm{SI}-\mathrm{C}-\mathrm{H}$, (c) SI-C-S, (d) $\mathrm{SI}-\mathrm{C}-\mathrm{S}-\mathrm{H}_{2} \mathrm{O}_{2}$.

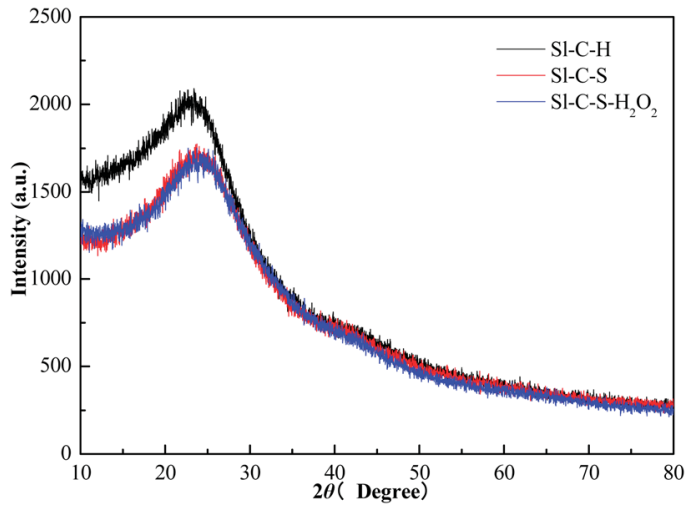

Fig. 3 X-ray diffraction patterns of the catalysts.

$1616 \mathrm{~cm}^{-1}$ for the three catalysts was ascribed to the stretching vibration absorption of the $\mathrm{C}=\mathrm{C}$ double bond of the aromatic ring, which indicated that the catalyst body still contained an aromatic ring in its skeleton structure. ${ }^{15}$ In comparison to the absorption peaks in the spectrum of Sl-C-H, the absorption peaks of Sl-C-S at $1169 \mathrm{~cm}^{-1}$ and $1034 \mathrm{~cm}^{-1}$ were different, and this was ascribed to the corresponding asymmetric stretching vibration and symmetrical stretching vibration of $-\mathrm{SO}_{3} \mathrm{H}$ and $\mathrm{O}=\mathrm{S}=\mathrm{O}$ bonds, indicating that the sulfonic acid groups were attached to the catalyst successfully. The stretching vibration peak of $\mathrm{C}=\mathrm{O}$ at $1705 \mathrm{~cm}^{-1}$ indicated the presence of carboxyl groups. The broad absorption band at approximately $3419 \mathrm{~cm}^{-1}$ corresponded to the stretching vibration of the hydroxyl groups., ${ }^{9,31}$ The FT-IR spectrum of Sl-C-S$\mathrm{H}_{2} \mathrm{O}_{2}$ showed clearer and stronger signals from acidic functional groups $(-\mathrm{COOH},-\mathrm{OH})$ than did the FT-IR spectrum of Sl-C-S.

From the results of SEM and XRD, it could be clearly observed that the surface structures of sodium lignosulfonatebased solid acids were severely damaged after carbonization and sulfonation, but the carbon skeletons of the three solid acids were almost the same. The FT-IR results revealed the difference regarding the functional groups among the three solid acids: different acidic functional groups. Moreover, the solid acid catalyst had a complex fused ring structure. ${ }^{32}$ Thus, during the different preparation processes, the variation of the functional groups of the three catalysts was exhibited in Fig. 5.

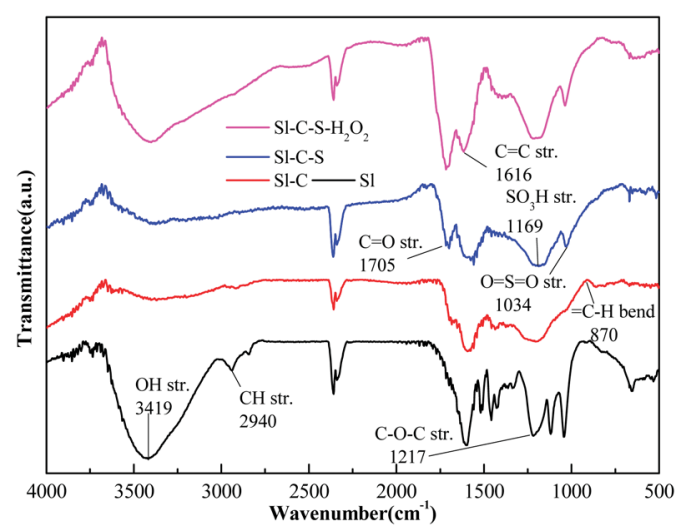

Fig. 4 FT-IR diffraction patterns of the catalysts and raw material. 
It was reported that the phenolic hydroxyl groups and carboxyl groups in the carbon material, which were capable of adsorbing cellulose and water molecules effectively, and the $\mathrm{SO}_{3} \mathrm{H}$ groups bonded to the carbon material could decompose hydrogen bonds and hydrolyze the $\beta-1,4-$ glycosidic bonds in the adsorbed cellulose molecules. ${ }^{18}$ Based on this report, it could be predicted that the main catalysis effects of phenolic hydroxyl groups and carboxyl groups in our carbon-based solid acids were absorbing hemicellulose and water molecules, and the $\mathrm{SO}_{3} \mathrm{H}$ groups could decompose the bonds in the adsorbed hemicellulose molecules and released xylose or xylo-oligosaccharides.

Through the results of Fig. 1 and 5, the relationship between the properties of the three solid acid functional groups and the xylose selectivity was analysed. The simplest solid acid Sl-C-H could be obtained by direct carbonization of $\mathrm{Sl}$ and ion exchange with $\mathrm{HCl}$. However, only a small amount of acidic functional groups $\left(-\mathrm{SO}_{3} \mathrm{H},-\mathrm{OH},-\mathrm{COOH}\right)$ were attached on the surface of the solid acid, resulting in the low xylose selectivity of corncob hydrolysis showed in Fig. 1. To introduce more acidic functional groups, sulfuric acid was used to sulfonate the Sl-C, introducing more sulfonic acid groups $\left(-\mathrm{SO}_{3} \mathrm{H}\right)$ onto the catalyst. Furthermore, the oxidation of Sl-C-S by hydrogen peroxide was carried out to obtain more carboxyl and hydroxyl groups $(-\mathrm{COOH},-\mathrm{OH})$. The results were consistent with the performances of Sl-C-S and Sl-C-S$\mathrm{H}_{2} \mathrm{O}_{2}$ in corncob hydrolysis (Fig. 1), and the results were also consistent with those of FT-IR analysis (Fig. 4). The oxidation reaction by hydrogen peroxide was used to introduce more weakly acidic groups (such as $-\mathrm{COOH}$ and $-\mathrm{OH}$ ) instead of $-\mathrm{SO}_{3} \mathrm{H}$, which was confirmed by no change in the content of $-\mathrm{SO}_{3} \mathrm{H}$ before and after the hydrogen peroxide treatment (as shown in the elemental analysis in Table 1). However, the weak acidic groups introduced by the hydrogen peroxide treatment did not result in a remarkable increase in the total xylose yield (84.2\% with Sl-C-S- $\mathrm{H}_{2} \mathrm{O}_{2}$ vs. $78 \%$ with Sl-C-S), but significantly increased the xylose selectivity (86.75\% for Sl-C-S- $\mathrm{H}_{2} \mathrm{O}_{2}$ vs. $68 \%$ for Sl-C-S); the xylose result for SlC-S- $\mathrm{H}_{2} \mathrm{O}_{2}$ is shown in Fig. 1.

\section{Optimization of preparation conditions for Sl-C-S- $\mathrm{H}_{2} \mathrm{O}_{2}$}

The effects of varying the carbonization temperature of the corncob hydrolysis are shown in Fig. 6. The xylose yield obtained was treated by $4 \% \mathrm{H}_{2} \mathrm{SO}_{4}$. The carbonization of sodium

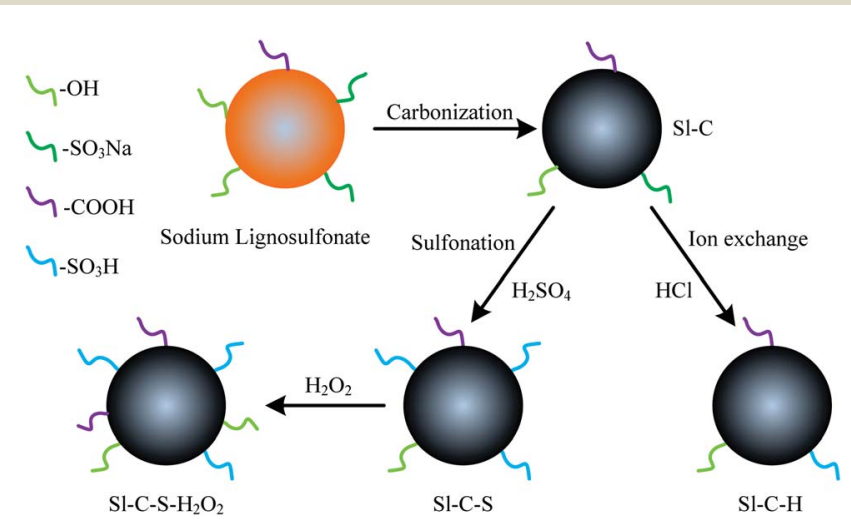

Fig. 5 Reaction formula for catalyst preparation. lignosulfonate is a process that includes simultaneous thermal decomposition and polycondensation reactions. ${ }^{33}$ It was observed that when the temperature was below $250{ }^{\circ} \mathrm{C}$, the yield of xylose increased with the increasing temperature. This was due to the formation of carbonized amorphous structures, which accommodated more acidic functional groups $\left(-\mathrm{SO}_{3} \mathrm{H}\right.$, $-\mathrm{COOH},-\mathrm{OH})$ for the hydrolysis reaction. A further increase in the temperature resulted in the reduction of the xylose yield, which was due to the destruction of the optimum carbon structure, resulting in decreased availability of the active site. To further verify this result, acid-base titration experiments were conducted. In Table $\mathrm{S} 1, \dagger$ it can be observed that when the temperature was lower than $250{ }^{\circ} \mathrm{C}$, the $\mathrm{SO}_{3} \mathrm{H}$ and total acid content were increased, and a further increase in the temperature resulted in a decreased acid content. It was found that the effects of the carbonization temperatures were consistent with the results of the acid-base titration. The optimal carbonization temperature and reaction time of the hydrolysis process were determined to be $250{ }^{\circ} \mathrm{C}$ and $6 \mathrm{~h}$, producing the optimal xylose yield of $83.5 \%$.

The effects of $\mathrm{H}_{2} \mathrm{O}_{2}$ concentration, oxidation reaction time, reaction temperature and the solid/liquid ratio on the catalytic activity of Sl-C-S- $\mathrm{H}_{2} \mathrm{O}_{2}$ were studied by a single factor control method as shown in Fig. S3. $\dagger$ The xylose yield gradually increased with the increasing $\mathrm{H}_{2} \mathrm{O}_{2}$ concentration and reached the highest level when $10 \% \mathrm{H}_{2} \mathrm{O}_{2}$ was applied. This was attributed to the improved availability of carboxylic acid and hydroxyl functional groups on the catalyst surface during the treatment process, which could enhance the catalytic activity for the hydrolysis reaction. Further increasing the $\mathrm{H}_{2} \mathrm{O}_{2}$ concentration beyond $10 \%$ did not result in enhancement of the xylose yield. According to Fig. S3(b), $\uparrow$ the highest xylose yield was obtained when the reaction time was $90 \mathrm{~min}$. The increase of oxidation temperature could improve the catalytic activity when the oxidation temperature was below $50{ }^{\circ} \mathrm{C}$. The change in this effect above $50{ }^{\circ} \mathrm{C}$ was due to the rapid decomposition of $\mathrm{H}_{2} \mathrm{O}_{2}$ at higher temperature. The effect of the solid-liquid ratio was similar to that of the reaction time, indicating that excessive content of $\mathrm{H}_{2} \mathrm{O}_{2}$ was not necessary to promote the oxidation process. Based on this analysis, the optimized reaction

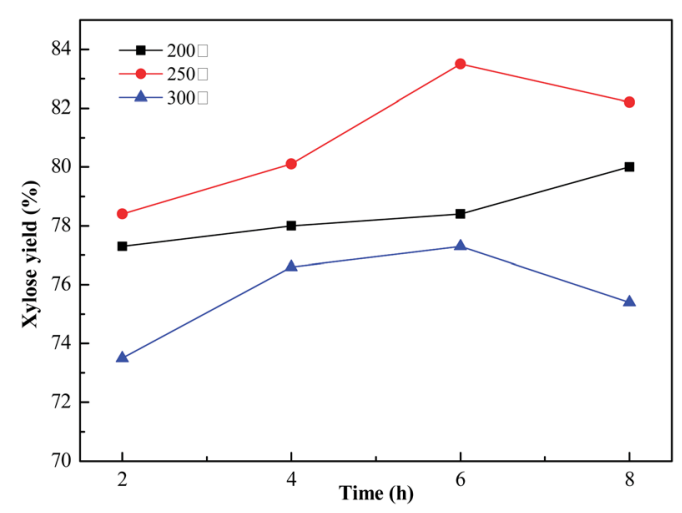

Fig. 6 Effect of carbonization temperature and time on the catalysis of corncob hydrolysis. Oxidation condition: $1 \mathrm{~g}$ of SI-C-S, $50 \mathrm{~mL}$ of $10 \%$ $\mathrm{H}_{2} \mathrm{O}_{2}$ at $50{ }^{\circ} \mathrm{C}$ for $90 \mathrm{~min}$. 
conditions for the catalyst Sl-C-S- $\mathrm{H}_{2} \mathrm{O}_{2}$ were determined to be $10 \% \mathrm{H}_{2} \mathrm{O}_{2}, 50{ }^{\circ} \mathrm{C}$ temperature, and 90 min reaction time with a solid-liquid ratio of $1: 75 \mathrm{~g} \mathrm{~mL}^{-1}$. The highest yield of xylose obtained with these conditions was $84.2 \%$.

In the study of hydrolysis of hemicellulose in biomass catalyzed by carbon-based solid acid, Zhang prepared the solid acid catalyst $\mathrm{Fe}_{3} \mathrm{O}_{4} / \mathrm{C}-\mathrm{SO}_{3} \mathrm{H}$ to catalyze corncob hydrolysis; only a $44.3 \%$ xylose yield was obtained when the hydrolysis was carried out at $160{ }^{\circ} \mathrm{C}$ for $16 \mathrm{~h}^{.22} \mathrm{Xu}$ used glucose and $p$-toluenesulfonic acid as raw materials to prepare a solid acid (Gp$\mathrm{SO}_{3} \mathrm{H}-\mathrm{H}_{2} \mathrm{O}_{2}$ ), ${ }^{23}$ and a xylose yield of $78 \%$ (after sulfuric acid post-hydrolysis) was obtained when the hydrolysis of corncob was carried out at $140{ }^{\circ} \mathrm{C}$ for $14 \mathrm{~h}$. Zhong prepared the $\mathrm{SO}_{4}{ }^{2-} /$ $\mathrm{Fe}_{2} \mathrm{O}_{3}$ solid acid catalyst and catalyzed the hydrolysis of wheat straw at $140{ }^{\circ} \mathrm{C}$ for $4 \mathrm{~h}$; the yield of xylose was $63.5 \%$ (after sulfuric acid post-hydrolysis). ${ }^{24}$ In our study, the xylose selectivity was significantly improved, and the reaction condition was mild.

\section{Characterization of corncob feedstock and residue}

The surface morphologies of the corncob raw material and the corncob residue after pretreatment are shown in Fig. 7. The color of the corncob changed from light yellow to dark brown after the hydrolysis reaction. Meanwhile, the relatively smooth and dense surface structure of the feedstock changed to a structure having irregular gullies with loose holes. This was mainly due to the decomposition of hemicellulose in the cell walls to form water-soluble xylose during the catalytic hydrolysis.

Both the corncob and residue produced a significant XRD peak at approximately $22.5^{\circ}$, which was attributed to the 002 plane crystal diffraction peak of cellulose as shown in Fig. S4. $\dagger$ The diffraction intensity at $2 \theta=17.5^{\circ}$ corresponded to the 101 plane diffraction intensity peak associated with the amorphous region of cellulose. The diffraction intensity at $2 \theta=22.5^{\circ}$ corresponded to the crystalline cellulose. According to eqn (2), the crystallinity indices of the corncob and the hydrolysis residues were $31.3 \%$ and $41.7 \%$, respectively. The increased crystallinity
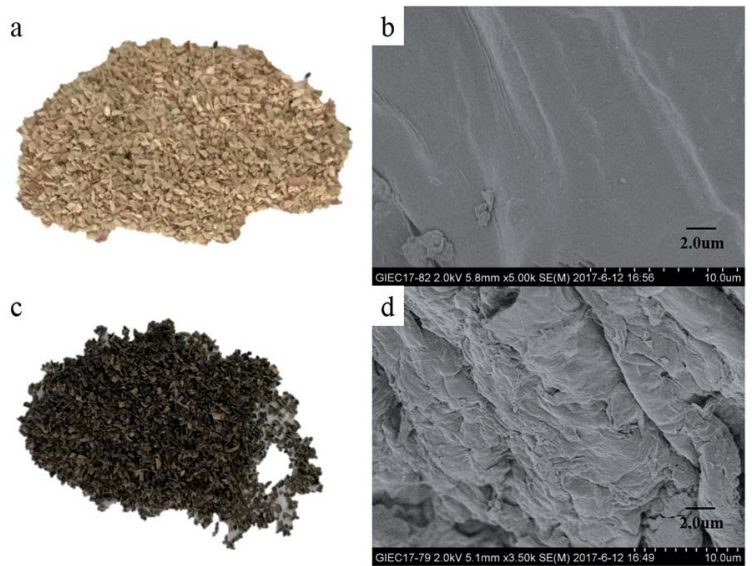

Fig. 7 The light and SEM images of corncob and residues: (a) corncob, (b) SEM of corncob, (c) residue, (d) SEM of residue.
Table 2 Composition analysis of residues produced after corncob hydrolysis with the three catalysts

\begin{tabular}{|c|c|c|c|c|}
\hline $\begin{array}{l}\text { Corncob } \\
\text { residue }\end{array}$ & $\begin{array}{l}\text { Cellulose } \\
(\%)\end{array}$ & $\begin{array}{l}\text { Hemicellulose } \\
(\%)\end{array}$ & $\begin{array}{l}\text { Lignin } \\
(\%)\end{array}$ & $\begin{array}{l}\text { Retention } \\
\text { rate of } \\
\text { cellulose } \\
(\%)\end{array}$ \\
\hline Sl-C-H & $50.67 \pm 0.73$ & $16.57 \pm 0.57$ & $28.57 \pm 0.31$ & - \\
\hline Sl-C-S & $55.71 \pm 1.07$ & $10.16 \pm 1.03$ & $30.42 \pm 0.38$ & - \\
\hline Sl-C-S- $\mathrm{H}_{2} \mathrm{O}_{2}$ & $58.03 \pm 0.87$ & $6.97 \pm 0.88$ & $31.62 \pm 0.45$ & 82.5 \\
\hline
\end{tabular}

and sharper crystal peaks were both due to the hydrolysis of hemicellulose, whereas the crystalline cellulose and lignin remained in the corncob.

When compared with those in the raw material, the relative contents of cellulose and lignin in the residue increased after hydrolysis, whereas the content of hemicellulose decreased (Table 2). This was because the degree of hydrolysis of hemicellulose was greater than those of cellulose and lignin. As can be seen in Table 2, the contents of cellulose and lignin in the corncob residue subjected to catalysis by Sl-C-S- $\mathrm{H}_{2} \mathrm{O}_{2}$ were the highest and reached $58.03 \%$ and $31.62 \%$, respectively. These were compared to the lowest hemicellulose content of $6.97 \%$, which suggested a greater hydrolysis degree for hemicellulose. This was consistent with the result shown in Fig. 1, in which the highest yield of hydrolyzed xylose was obtained using Sl-C-S$\mathrm{H}_{2} \mathrm{O}_{2}$. By calculation, the retention rate of cellulose was $82.5 \%$, which indicated that a large amount of cellulose was not hydrolyzed into glucose.

\section{Reusability of the catalyst}

The reusability of the catalyst is an important property for the economical industrial application of solid acid catalysts. ${ }^{34}$ To investigate the reusability of Sl-C-S- $\mathrm{H}_{2} \mathrm{O}_{2}$, which was prepared under the optimum conditions, evaluation experiments were carried out at $130{ }^{\circ} \mathrm{C}$ for $12 \mathrm{~h}$. After the hydrolysis reaction, the catalyst was washed and filtered through a sand-core funnel several times before drying at $105{ }^{\circ} \mathrm{C}$ for $6 \mathrm{~h}$ and then, it was separated by a 200-mesh sieve. It can be seen from Fig. 8 that

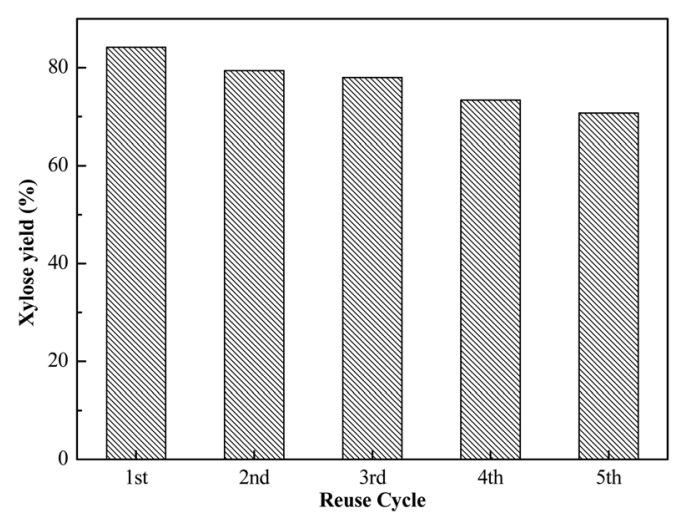

Fig. 8 Xylose yields from corncob hydrolysis catalyzed by recycled SIC-S $-\mathrm{H}_{2} \mathrm{O}_{2}$. 
the yield of xylose decreased gradually from $84.2 \%$ to $70.7 \%$, and the reduction in the catalytic ability was better than that in the previous report by $\mathrm{Xu},{ }^{23}$ who reported that the yield of xylose decreased from $77.5 \%$ to $65.0 \%$ after 4 cycles of usage. The elemental analysis and acid-base titration results for Sl-C-S$\mathrm{H}_{2} \mathrm{O}_{2}$ after reuse are shown in Table S2. $\dagger$ It was found that the total acid content after 5 cycles of reuse was still very high, and it was $90.79 \%$ of the initial total acid content.

\section{Conclusions}

A novel carbon-based solid acid catalyst with high catalytic activity, high selectivity and reusability was synthesized from waste lignosulfonate. The solid acid catalyst synthesized through the processes of carbonization, sulfonation by concentrated sulfonic acid and modification by $\mathrm{H}_{2} \mathrm{O}_{2}$ was rich in acidic functional groups such as $-\mathrm{COOH},-\mathrm{OH}$, and $-\mathrm{SO}_{3} \mathrm{H}$. Under the optimized preparation conditions for the catalyst, the catalyst showed a high catalytic activity and selectivity for the hydrolysis hemicellulose in corncob with an $84.2 \%$ yield of xylose, $82.5 \%$ cellulose retention rate and only a few byproducts. Meanwhile, the catalyst showed good stability and reusability, as it could be used four times with only a slight decrease in the catalytic ability. Based on this research, we can conclude that the synthesized catalyst is excellent for pretreatment of lignocellulose, and it facilitates a new method for establishing a sugar platform.

\section{Conflicts of interest}

There are no conflicts to declare.

\section{Acknowledgements}

This study was supported financially by the National Natural Science Foundation of China (21376241, 51676193, 51506207, 51561145015 and 21476233), the Youth Innovation Promotion Association, CAS (No. 2017401) and the Key Project of Natural Science Foundation of Guangdong Province (No. 2015A030311022). N. Leksawasdi gratefully acknowledges the financial support and/or in-kind assistance from the Sino-Thai National Research Council of Thailand (NRCT). The authors further acknowledge support from the Project Funding of National Research University-Chiang Mai University (NRUCMU) and the National Research University-Office of Higher Education Commission (NRU-OHEC), the Non-Food Agricultural Research Cluster, and CMU Mid-Career Research Fellowship program (Grant Number: W566_21022560).

\section{References}

1 F. Isikgor and C. Becer, Polym. Chem., 2016, 6, 4497-4559.

2 H. S. Kambo and A. Dutta, Energy Convers. Manage., 2015, 105, 746-755.

3 Y. J. Zhang, P. Y. Bi, J. C. Wang, P. W. Jiang, X. P. Wu, H. Xue, J. X. Liu, X. G. Zhou and Q. X. Li, Appl. Energy, 2015, 150, 128137.
4 D. Yamaguchi and M. Hara, Solid State Sci., 2010, 12, 10181023.

5 X. Zhang, K. Wilson and A. F. Lee, Chem. Rev., 2016, 116, 12328-12368.

6 A. Esteghlalian, A. Hashimoto, J. Fenske and M. Penner, Bioresour. Technol., 1997, 59, 129-136.

7 J. Söderström, L. Pilcher, M. Galbe and G. Zacchi, Appl. Biochem. Biotechnol., 2003, 108, 127-140.

8 W. Qi, S. Zhang, Q. Xu, H. Li, Z. Ren, T. Li and Y. Yan, Chem. Eng. Technol., 2009, 32, 534-540.

9 I. F. Nata, C. Irawan, P. Mardina and C.-K. Lee, J. Solid State Chem., 2015, 230, 163-168.

10 L. D. Borges, N. N. Moura, A. A. Costa and P. R. S. Braga, Appl. Catal., A, 2013, 450, 114-119.

11 S. A. Fernandes, A. L. Cardoso and M. J. da Silva, Fuel Process. Technol., 2012, 96, 98-103.

12 H. Yan, Y. Yang, D. Tong, X. Xiang and C. Hu, Catal. Commun., 2009, 10, 1558-1563.

13 I. A. L. Bassan, D. R. Nascimento, R. A. S. San Gil, M. I. P. da Silva, C. R. Moreira, W. A. Gonzalez, A. C. Faro, T. Onfroy and E. R. Lachter, Fuel Process. Technol., 2013, 106, 619-624.

14 J. Y. Park, Z. M. Wang, D. K. Kim and J. S. Lee, Renewable Energy, 2010, 35, 614-618.

15 G. Chen and B. Fang, Bioresour. Technol., 2011, 102, 26352640.

16 S. Suganuma, K. Nakajima, M. Kitano, D. Yamaguchi, H. Kato, S. Hayashi and M. Hara, Solid State Sci., 2010, 12, 1029-1034.

17 K. N. Satoshi Suganuma, M. Kitano, D. Yamaguchi, S. H. Hideki Kato and M. Hara, Green Chem., 2005, 438, 178.

18 S. Suganuma, K. Nakajima, M. Kitano and D. Yamaguchi, J. Am. Chem. Soc., 2008, 130, 12787-12793.

19 S. Li and X. J. Pan, Energy Environ. Sci., 2012, 5, 6889-6894.

20 Y. Lian, L. Yan, Y. Wang and X. Qi, Acta Chimica Sinica, 2014, 72, 502-507.

21 S. G. Shen, B. Cai, C. Y. Wang, H. M. Li, G. Dai and H. F. Qin, Appl. Catal., A, 2014, 473, 70-74.

22 X. Zhang, X. Tan, Y. Xu, W. Wang, L. Ma and W. Qi, BioResources, 2016, 11, 10014-10029.

23 Y. Xu, X. Li and X. C. Zhang, BioResources, 2016, 11, 1046910482.

24 C. Zhong, C. Wang, F. Huang, F. Wang, H. Jia, H. Zhou and P. Wei, Carbohydr. Polym., 2015, 131, 384-391.

25 D. Lee, Molecules, 2013, 18, 8168-8180.

26 J. D. Zhu and L. H. Gan, Appl. Chem. Ind., 2016, 45, 14991502.

27 F. Liang, Y. Song, C. Huang and B. Chen, New Chem. Mater., 2014, 42, 86-89.

28 A. Sluiter, B. Hames, R. Ruiz, C. Scarlata and J. Sluiter, Technical Report NREL/TP-510-42618, 2008.

29 L. Segal, J. Creely, A. Martin and C. Conrad, Text. Res. J., 1959, 29, 786-794.

30 B. Zhang, J. Ren, X. Liu, Y. Guo, Y. Guo, G. Lu and Y. Wang, Catal. Commun., 2010, 11, 629-632.

31 X. Liang, H. Xiao, Y. Shen and C. Qi, Mater. Lett., 2010, 64, 953-955. 
32 M. Hara, T. Yoshida, A. Takagaki, T. Takata, J. N. Kondo, S. Hayashi and K. Domen, Angew. Chem., 2004, 43, 29552958.
33 M. Brebu, G. Cazacu and O. Chirila, Cellul. Chem. Technol., 2011, 45, 43-50.

34 J. Zhao, C. Zhou, C. He, Y. Dai, X. Jia and Y. Yang, Catal. Today, 2016, 264, 123-130. 